\title{
A Performance Study of Proactive, Reactive and Hybrid Routing Protocols using Qualnet Simulator
}

\author{
Subramanya Bhat.M \\ Dept. of Electronic Science \\ Bangalore University \\ Bangalore -560056
}

\author{
Shwetha.D \\ Dept. of Electronic Science \\ Bangalore University \\ Bangalore -560056
}

\author{
Devaraju.J.T \\ Dept. of Electronic Science \\ Bangalore University \\ Bangalore -560056
}

\begin{abstract}
The advancement in information technology and the need for large-scale communication infrastructures has triggered the era of Wireless Sensor Networks (WSNs). Mobile ad-hoc network (MANET) is a network of wireless mobile nodes which communicate with each other without any centralized control or established infrastructure. Routing is the process of selecting paths in a network along which data is to be sent. Routing is a critical task in MANET where the nodes are mobile. Dynamic and reliable routing protocols are required in the ad-hoc wireless networks, as they have no infrastructure (base station) and their network topology changes. There are various protocols for handling the routing problem in the ad-hoc wireless network environment. In this paper focus is given on studying the performance evaluation of various routing protocols using Qualnet simulator 5.0.2. The performance of the proactive, reactive and hybrid protocols are analyzed with different node densities for mobile and stationary nodes. The metrics used for the performance evaluation include average jitter, throughput, packet delivery ratio and average end to end delay.
\end{abstract}

\section{Keywords}

Proactive, Reactive, Hybrid, Performance Evaluation, Qualnet, End-to-end Delay, Throughput, Jitter, Packets delivery ratio.

\section{INTRODUCTION}

In recent years, the progress of communication technology has made wireless devices smaller, less expensive and more powerful. The rapid technology advance has provoked great growth in mobile devices connected to the Internet. Hence various wireless network technologies such as $3 \mathrm{G}, 4 \mathrm{G}$ of cellular network, ad-hoc, IEEE 802.11 based wireless local area network (WLAN) and Bluetooth are used. IEEE 802.15.4 is a very important technology of ubiquitous wireless sensor network [1]. MANET is a collection of nodes, which form an arbitrary and dynamic network with wireless links. Links between the nodes can change with time, new nodes can join the network and other nodes can leave it [2].

The set of applications for MANETs is diverse, ranging from small static networks that are constrained by power sources to large-scale, mobile, highly dynamic networks. A key challenge in ad-hoc network design is to develop a high quality and efficient routing protocol which can be used to communicate using mobile nodes [2]. Unfixed topology in ad-hoc networks results in finding the delivery path dynamically, maintain the integrity and stability of the path during data delivery process.
This ensures the data packets are transferred to the destination node completely. The traditional routing mechanisms and protocols of wired network are inapplicable to ad -hoc networks, which initiated the need to use a dynamic routing mechanism in ad-hoc network [3].

The key factor that determines, how efficiently a multi-hop wireless network reacts to topology changes and node mobility is the routing protocol that provides routes for every node in the network. Routing is performed for many kinds of networks, including the telephone network (Circuit switching), electronic data networks (such as the Internet) and transportation networks. This article is concerned primarily with routing in electronic data networks which uses packet switching technology. In packet switching networks, routing directs packet forwarding from their source toward their ultimate destination through intermediate nodes. This is done using hardware devices called routers, bridges, gateways, firewalls or switches. Generalpurpose computers can also forward packets and perform routing, though they are not specialized hardware devices they may suffer from limited performance. The routing process usually directs data packets on the basis of routing tables which maintain a record of the routes to various network destinations. Most routing algorithms use only one path at a time, but multipath routing techniques enable the use of multiple alternative paths [4].

In this work performance evaluation of various routing protocols like Optimized Link State Routing protocol (OLSR), Ad-hoc On-demand Distance Vector routing (AODV), Dynamic Source Routing (DSR), Location Aided Routing (LAR) and Zone Routing Protocol (ZRP) are studied using Qualnet 5.0.2 network simulator [5] for $25,50,75,100,150,200$ and 250 stationary and mobile nodes. The rest of this paper is organized as follows: in section 2 brief introductions to various routing techniques is discussed. In section 3 reviews of literature and comments on related work is presented. Simulation platform used in the work is discussed in section 4. In section 5 the results of the performance evaluation are thoroughly discussed. Conclusion is given in section 6 .

\section{ROUTING TECHNIQUES}

Routing is the process of selecting paths in a network along which data to be sent. In an ad-hoc network, mobile nodes communicate with each other using multihop wireless links. There is no stationary infrastructure; each node in the network also acts as a router, forwarding data packets for other nodes. A central challenge in the design of ad-hoc networks is the development of dynamic routing protocols that can efficiently 
find routes between two communicating nodes. The routing protocol must be able to keep up with the high degree of node mobility that often changes the network topology drastically and unpredictably [1]. Ad-hoc radio networks have various implementation areas like military, emergency, conferencing and sensor applications. Each of these application areas has their specific requirements for routing protocols. In military applications low probability of detection and interception is a key factor, in sensor applications low or minimum energy consumption is a precondition for an autonomous operation. In conference applications a guaranteed quality of service for multimedia services is a needed feature. All these application areas have some features and requirements for protocols in common. Because of multiple and diverse ad-hoc protocols, there is an obvious need for a general taxonomy to classify protocols considered [6].

Routing protocols are divided into two categories namely, proactive and reactive.

\subsection{Proactive routing protocols:}

In proactive routing, each node has one or more tables that contain the latest information of the routes to any other node in the network. Various table-driven protocols differ in the way how the information propagates through all nodes in the network when topology changes. The proactive routing protocols are not suitable for larger networks as they need to maintain each and every node entries in the routing table. This causes more overhead in the routing table leading to consumption of more bandwidth. Examples of such schemes are the conventional routing schemes: Destination sequenced distance vector (DSDV), Bellman ford protocol, Optimized link state protocol (OLSR) etc.

\subsubsection{Optimized Link State Routing (OLSR):}

It is a proactive routing protocol where the routes are always available when needed. OLSR is an optimized version of a pure link state protocol. The topological changes cause the flooding of the topological information to all available hosts in the network. To reduce the possible overhead in the network protocol multipoint relays (MPR) are used. Reducing the time interval for the control messages transmission brings more reactivity to the topological changes [7].

OLSR uses two kinds of the control messages namely hello and topology control. Hello messages are used for finding the information about the link status and the host's neighbours. Topology control messages are used for broadcasting information about its own advertised neighbours, which includes at least the MPR selector list [7].

\subsection{Reactive protocols (On-demand):}

Reactive routing is also known as on-demand routing protocol since they do not maintain routing information or routing activity at the network nodes if there is no communication. If a node wants to send a packet to another node then this protocol searches for the route in an on-demand manner and establishes the connection in order to transmit and receive the packet. The route discovery occurs by flooding the route request packets throughout the network. Examples of reactive routing protocols are the Ad-hoc On-demand Distance Vector routing (AODV), Location Aided Routing (LAR) and Dynamic Source Routing (DSR) [8].

\subsubsection{Adhoc On-demand Distance Vector (AODV):}

This protocol performs route discovery using control messages route request (RREQ) and route reply (RREP) whenever a node wishes to send packets to destination. When source node receives the route error (RERR) message, it can reinitiate route. Neighbourhood information is obtained from broadcasted hello packets. It is a flat routing protocol which does not need any central administrative system to handle the routing process. AODV tends to reduce the control traffic messages overhead at the cost of increased latency in finding new routes. The AODV protocol is a loop free and uses sequence numbers to avoid the infinity counting problem which is typical to the classical distance vector routing protocols [9].

\subsubsection{Location Aided Routing (LAR):}

Location aided routing [10], is an enhancement to flooding algorithms to reduce flooding overhead. Most on-demand methods, including DSR and AODV use flooding to obtain a route to the destination. LAR aims to reduce the overhead to send the route requests only into a specific area, which is likely to contain the destination.

For this purpose the notions of expected zone and request zone are introduced. The expected zone covers the area in which the destination is expected. Since the expected zone need not contain the source node, a larger area must be covered by flooding. This expanded expected zone is called request zone and is used to restrict the flooding; i.e. only nodes that are part of the request zone can forward a route request. On unsuccessful route discoveries, the request zone may need to be expanded further, possibly covering the whole network. Such subsequent route requests increase the initial latency for connections. This results in a tradeoff between reduced overhead and increased latency which needs to be balanced carefully.

\subsubsection{Dynamic Source Routing (DSR):}

In dynamic source routing, source node floods a route request to all nodes which are in the wireless transmission range. Source routing protocol is composed of two main mechanisms to allow the discovery and maintenance of source routes in the ad hoc networks. To commence the route discovery mechanism, wireless node floods a route request to all nodes which are in the wireless transmission range. The initiator (source) and target (destination) of the route discovery is identified by each route request packet. The source node also provides a unique request identification number in its route request packet. For responding to the route request, the target node generally scans its own route cache for a route before sending the route reply toward the initiator node. However, if no suitable route is found, target will execute its own route discovery mechanism in order to reach toward the initiator [11]. The route maintenance mechanism is used when the source node is unable to use its current route to the destination due to changes in the network topology. In such case, the source has to use any other route to the destination. However, it may invoke the route discovery mechanism again to discover a new route. A routing entry in DSR contains all the intermediate nodes of the route rather than just the next hop information. A source puts the entire routing path in the data packet and the packet is sent through the intermediate nodes specified in the path. If the source does not have a routing path to the destination, then it performs a route discovery by flooding the network with a route request (RREQ) packet. Any node that has a path to the destination in question can reply to the RREQ 
packet by sending a route reply (RREP) packet. The reply is sent using the route recorded in the RREQ packet. The advantages of this routing are to provide multiple routes and avoid loop formation where as disadvantages are large end-to-end delay, scalability problems caused by flooding and source routing mechanisms.

\subsection{Hybrid Routing Protocols:}

Hybrid Routing Protocols combines the merits of proactive and reactive routing protocols by overcoming their demerits. In this section some light on hybrid routing protocol is given.

\subsubsection{Zone Routing Protocol (ZRP):}

Proactive routing uses excess bandwidth to maintain routing information, while reactive routing involves long route request delays. Reactive routing also inefficiently floods the entire network for route determination. The zone routing protocol (ZRP) [12] aims to address the problems by combining the best properties of both the proactive and reactive approaches. In ad-hoc network, it can be assumed that the largest part of the traffic is directed to nearby nodes. Therefore, ZRP reduces the proactive scope to a zone centered on each node. In a limited zone, the maintenance of routing information is easier. Further, the amount of routing information never used is minimized. In ZRP each node is assumed to maintain routing information only for those nodes that are within its routing zone. Because the updates are only propagated locally, the amount of update traffic required to maintain a routing zone does not depend on the total number of network nodes. A node learns its zone through a proactive scheme Intra zone Routing Protocol (IARP). For nodes outside the routing zone, Inter zone Routing Protocol (IERP) is responsible for reactively discovering routes to destinations located beyond a node's routing zone. The IERP is distinguished from standard flooding-based query/response protocols by exploiting the structure of the routing zone. The routing zones increase the probability that a node can respond positively to a route query. This is beneficial for traffic that is destined for geographically close nodes [12].

The performance of the routing protocols OLSR, AODV, DSR, LAR and ZRP are compared using Qualnet 5.0.2. Network Simulator with the metrics like average jitter, throughput, endto-end delay and packets delivery ratio.

\section{RELATED WORK}

A number of wireless routing protocols are proposed to provide communication in wireless environment using open source simulators. Performance comparison among some set of routing protocols are performed by the researchers in the beginning. Some among them are PAODV, AODV, CBRP, DSR and DSDV [13], performance of DSDV, DSR, AODV and TORA [14], performance of SPF, EXBF, DSDV, TORA, DSR and AODV [15], comparison of DSR and AODV [16], performance of STAR, AODV and DSR [17], comparison of AMRoute, ODMRP, AMRIS and CAMP [18], performance of DSR, CBT and AODV [19], comparison of DSDV, OLSR and AODV [20] and many more. These performance comparisons are carried out for ad-hoc networks. For this reason, evaluating the performance of wireless routing protocols in mobile WiMAX environment is still an active research area. In this paper an attempt is made to study and compare the performance of AODV, DSR, OLSR and ZRP routing protocols.
There are several other efforts related to the work under study. In the work of Perkins et.al [14], evaluation of DSR and AODV was studied with node density as 50 and 100 only using nS-2 network simulator. Another relative work has been presented by Broch et.al [15]. In the work [16], four ad-hoc routing protocols are evaluated using nS-2 for 50-node network models. Besides comparison of ad- hoc networks several other papers have dealt with ZRP and worked on the perfect zone radius value. Hass and Pearlman have done extensive research in ZRP [17]. In [18] DSR and AODV is evaluated using NS-2 network simulator for 50 and 100 nodes in a rectangular space. Various routing protocols are been analyzed in [19] including AODV and DSR. Extensive research in ZRP is done in [15] and they have concluded that no fixed value of ZRP's zone radius attribute exists, but every time it is dependent on the networks conditions.

To reduce the delay of route discovery [16] proposes query control schemes for ZRP. But they didn't consider the route reconfiguration in case of link failure. Proposed Work in [17] provides a topological map of the zone centered on a node to guarantee loop freedom, alternative paths in the case of route failure and disjoint paths. Idea in [20] is to reduce the network load by limiting the number of control packets when the protocol searches for a new route but constraint is that it does not consider the delay to acquire route to the destination.

In this paper packet size of 512 bytes are used, which makes the comparison between DSR and ZRP. The scenarios selected demonstrate the dynamic and adynamic behaviour of the mobile ad-hoc networks. An effort is made to compare the performance evaluation of proactive (OLSR), reactive (AODV, DSR, LAR) and also a hybrid (ZRP) routing protocols with various node densities for stationary and mobile nodes using Qualnet 5.0.2.network simulator.

\section{SIMULATION PLATFORM AND MODELS}

In this work Qualnet 5.0.2 network simulator [21] has been used to evaluate the performance of proactive (OLSR), reactive (AODV, DSR and LAR) and hybrid (ZRP) routing protocols of mobile ad-hoc networks. The physical medium used is 802.11 PHY with a data rate of $2 \mathrm{Mbps}$. The MAC protocol used is the 802.11 MAC protocol, configured for MANET mode. In this work wireless module of IEEE $802.11 \mathrm{~b}$ is used to enable mobility of the wireless nodes. IEEE $802.11 \mathrm{~b}$ support more accurate wireless models for propagation, path loss, multipath fading and reception on wireless networks. The simulations are carried out for network densities of 25, 50, 75,100, 150, 200 and 250 nodes respectively. The area considered for the above network densities are $500 \mathrm{~m}$ X 500m (25, 50, 75 and 100 nodes) and $1000 \mathrm{~m} \mathrm{X} \mathrm{1000m} \mathrm{(150,} 200$ and 250 nodes) for stationary nodes and nodes with mobility of $10 \mathrm{mps}$. Simulations are configured for the performance evaluation of different routing protocols with the metrics like packet delivery ratio, end to end delay, throughput and jitter at the destination for stationary and nodes with mobility of $10 \mathrm{mps}$ respectively as given in table1. 
Table 1. Scenario Parameters

\begin{tabular}{|l|l|l|}
\hline Routing protocols & AODV,DSR, LAR,OLSR \& ZRP \\
\hline Radio type & $802.11 \mathrm{~b}$ \\
\hline No. Of Channels & One \\
\hline Channel frequency & $2.4 \mathrm{GHz}$ & \\
\hline Mobility & None & Random Way Point \\
\hline Mobility speeds & None & 0 to $10 \mathrm{mps}$ \\
\hline Path loss model & Two Ray \\
\hline Energy model & Mica Motes \\
\hline Shadowing model & Constant \\
\hline Pause time & 30 second \\
\hline Simulation time & 300 second \\
\hline Battery model & Linear model \\
\hline Simulation area & $500 \mathrm{~m} \mathrm{X} \mathrm{500m}$ & $1000 \mathrm{~m} \mathrm{X} 1000 \mathrm{~m}$ \\
\hline Number of nodes & $25,50,75,100$ & $150,200,250$ \\
\hline Simulator & Qualnet 5.0 .2 & \\
\hline
\end{tabular}

\section{RESULTS AND DISCUSSIONS}

In this work various performance of routing protocols are studied for stationary and mobile nodes with different node densities. Figure1 \& 2 show the representative snapshots of Qualnet 5.0.2 simulation scenario of 100 nodes with mobility speed of 10mps for AODV routing protocol representing the route discovery mechanism and route maintenance respectively.

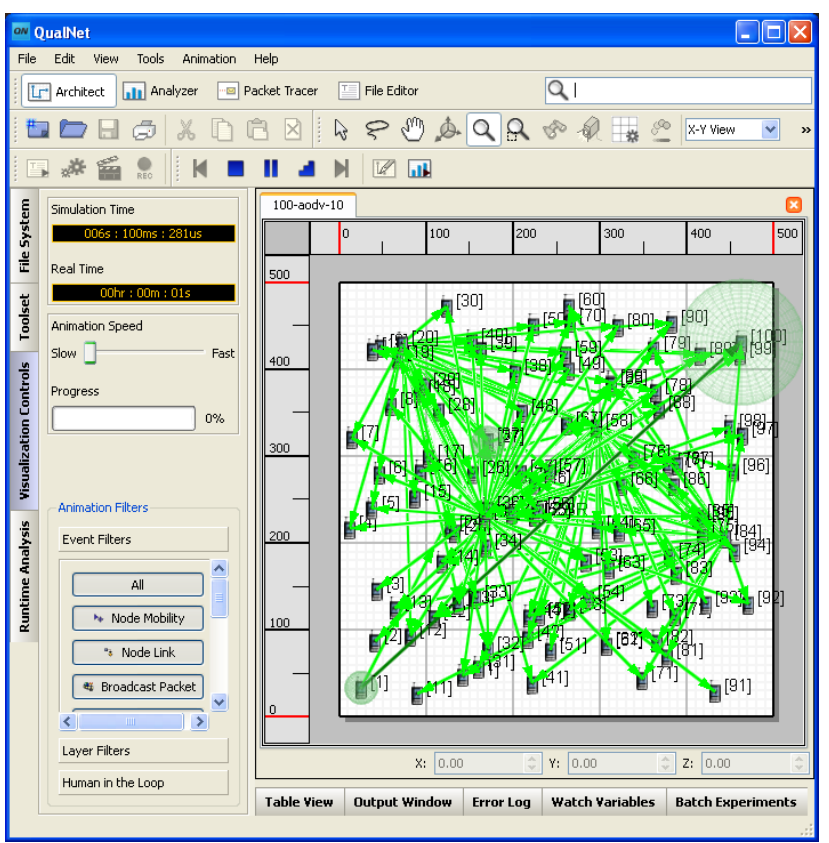

Fig 1: Snapshot of simulation scenario representing route discovery mechanism of 100 nodes for AODV routing.

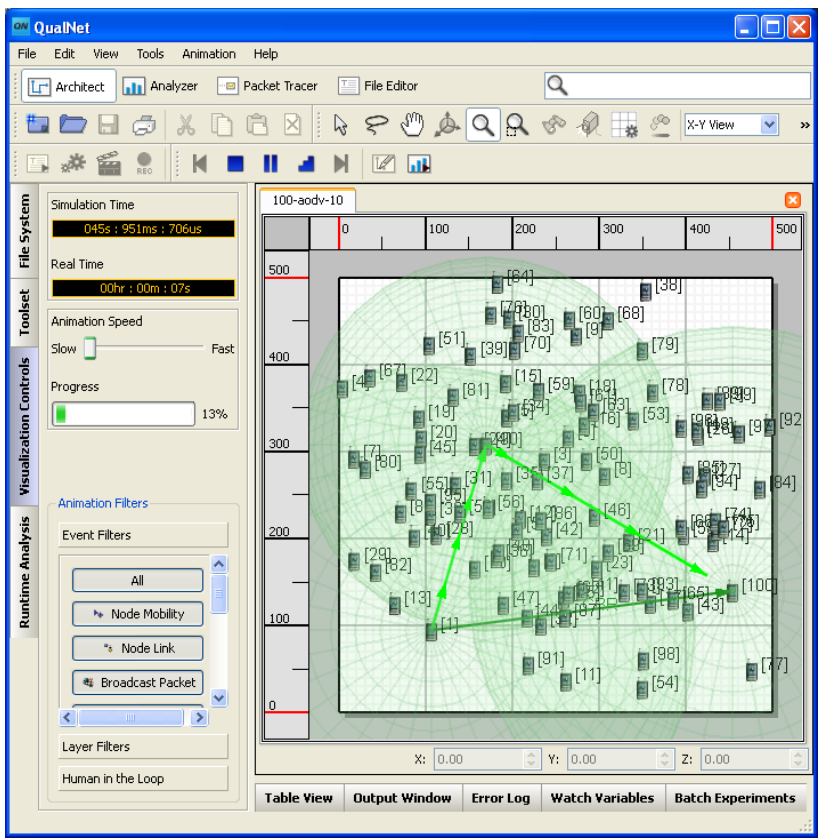

Fig 2: Snapshot of simulation scenario representing route maintenance mechanism of 100 nodes for AODV routing.

\subsection{Packet Delivery Ratio (PDR)}

The variation of PDR of various routing protocols for mobile and stationary nodes with respect to node densities 25, 50, 75 and 100 nodes is given in Figure 3 and for node densities 150, 200 and 250 nodes is given in Figure4. The PDR values of protocols considered for simulation with different node densities for both stationary and mobile nodes are given in table2.

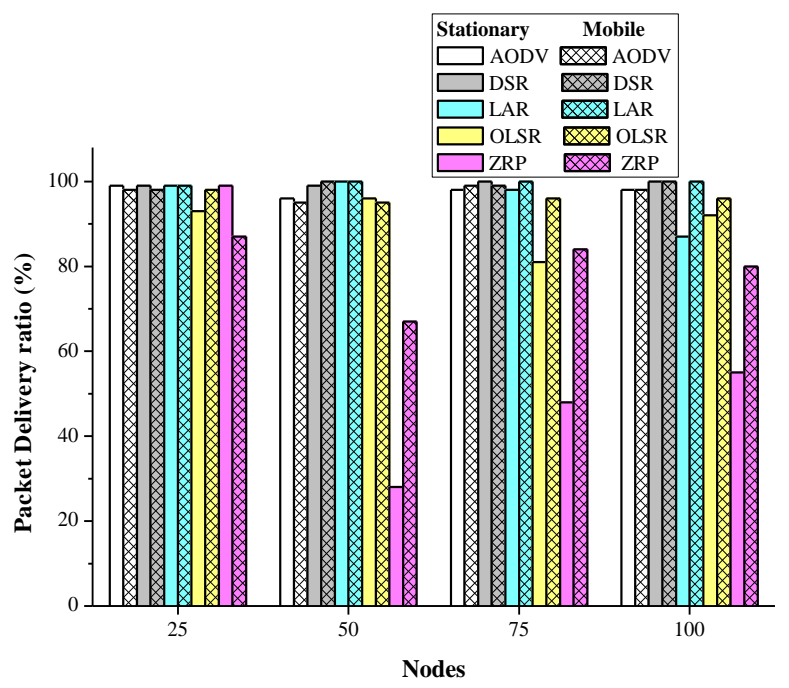

Fig 3: Packet Delivery Ratio for 25, 50, 75 and 100 stationary and mobile nodes 
Table 2. PDR of AODV, DSR, LAR, OLSR \& ZRP protocols for stationary and mobile nodes

\begin{tabular}{|c|c|c|c|c|c|c|c|c|c|c|}
\hline \multirow{2}{*}{ Nodes } & \multicolumn{2}{|c|}{ AODV (\%) } & \multicolumn{2}{c|}{ DSR (\%) } & \multicolumn{2}{c|}{ LAR (\%) } & \multicolumn{2}{c|}{ OLSR (\%) } & \multicolumn{2}{c|}{ ZRP (\%) } \\
\cline { 2 - 11 } & $\begin{array}{c}\text { Statio } \\
\text { nary } \\
\text { node }\end{array}$ & $\begin{array}{c}\text { Node with } \\
\text { mobility } \\
(\mathbf{1 0 m p s})\end{array}$ & $\begin{array}{c}\text { Statio } \\
\text { nary } \\
\text { node }\end{array}$ & $\begin{array}{c}\text { Node with } \\
\text { mobility } \\
(\mathbf{1 0 m p s})\end{array}$ & $\begin{array}{c}\text { Statio } \\
\text { nary } \\
\text { node }\end{array}$ & $\begin{array}{c}\text { Node with } \\
\text { mobility } \\
(\mathbf{1 0 m p s})\end{array}$ & $\begin{array}{c}\text { Statio } \\
\text { nary } \\
\text { node }\end{array}$ & $\begin{array}{c}\text { Node with } \\
\text { mobility } \\
(\mathbf{1 0 m p s})\end{array}$ & $\begin{array}{c}\text { Statio } \\
\text { nary } \\
\text { node }\end{array}$ & $\begin{array}{c}\text { Node with } \\
\text { mobility } \\
(\mathbf{1 0 m p s})\end{array}$ \\
\hline 25 & 99 & 98 & 99 & 98 & 99 & 99 & 93 & 98 & 99 & 87 \\
\hline 50 & 96 & 95 & 99 & 100 & 100 & 100 & 96 & 95 & 28 & 67 \\
\hline 75 & 98 & 99 & 100 & 99 & 98 & 100 & 81 & 96 & 48 & 84 \\
\hline 100 & 98 & 98 & 100 & 100 & 87 & 100 & 92 & 96 & 55 & 80 \\
\hline 150 & 96 & 94 & 100 & 100 & 100 & 97 & 69 & 72 & 20 & 38 \\
\hline 200 & 100 & 99 & 100 & 98 & 97 & 96 & 79 & 82 & 8 & 78 \\
\hline 250 & 100 & 96 & 99 & 95 & 99 & 96 & 75 & 68 & 39 & 49 \\
\hline
\end{tabular}

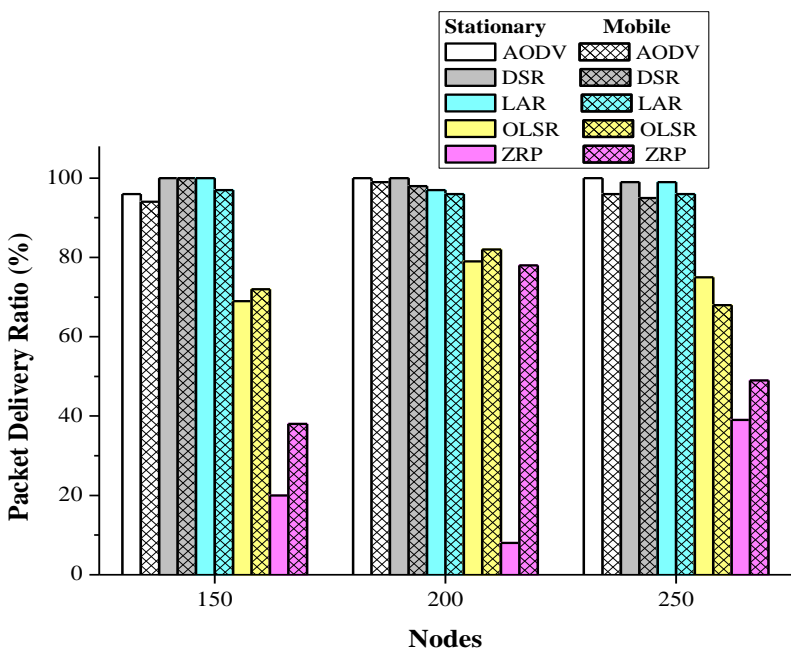

Fig 4: Packet Delivery Ratio for 150, 200 and 250 stationary and mobile nodes

It is evident from Figures 3 and 4 that the PDR of mobile nodes for AODV, DSR and LAR is almost same as compared to stationary nodes and also the variation in PDR is minimum with increase in node density. This is because route discovery and route maintenance is simple in these routing protocols [8]. For OLSR as the node density increases PDR decreases for both stationary and mobile nodes, this is due to the proactive nature of this protocol [7]. However for ZRP there is an improvement in PDR for mobile nodes as compared with stationary nodes this is due to implementation of hybrid protocol, which uses the advantages of both proactive routing tables and also dynamic routing techniques of reactive protocols [12].

\subsection{Average Jitter}

The variation of average jitter of various routing protocols for mobile and stationary nodes with respect to node densities 25 , 50, 75 and 100 nodes is given in Figure 5 and for node densities 150, 200 and 250 nodes is given in Figure6. The values of average jitter with different node densities for both stationary and mobile nodes are given in table2. OLSR shows least average jitter in 25, 50, 75 and 100 nodes scenario for mobile nodes as compared to other protocols. This is because OLSR is a proactive routing protocol which contains the route information in its routing table this reduces the search for new routes [7].

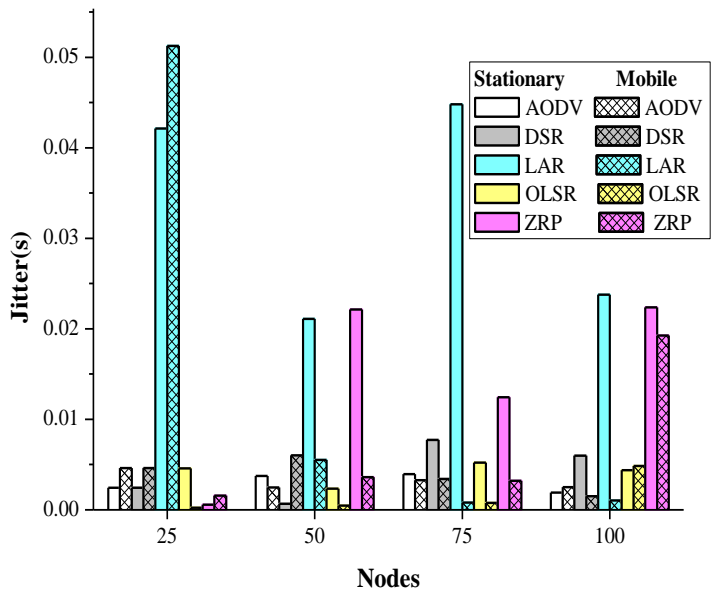

Fig 5: Average Jitter for 25, 50, 75 and 100 stationary and mobile nodes

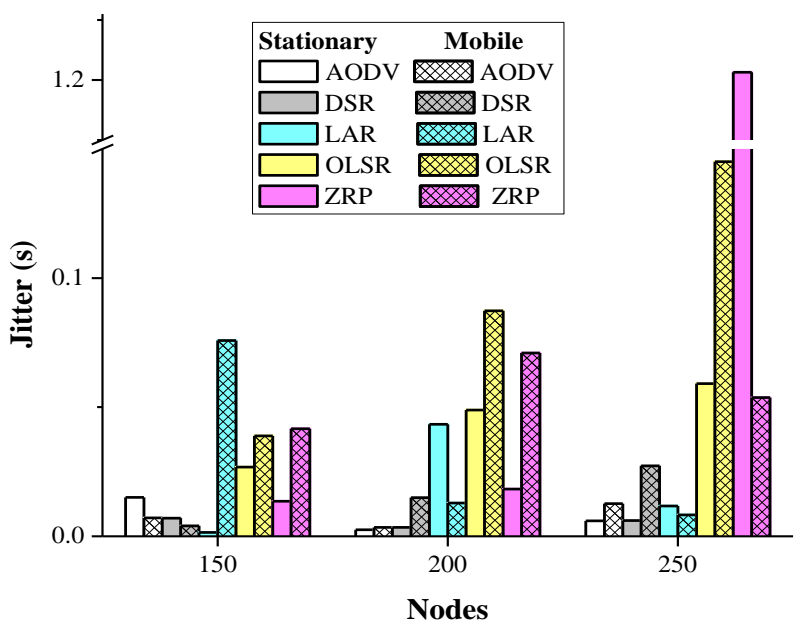

Fig 6: Average Jitter of AODV, DSR, LAR, OLSR \& ZRP protocols for 150, 200 and 250 stationary and mobile nodes 
Table 3. Average Jitter of AODV, DSR, LAR, OLSR \& ZRP protocols for stationary and mobile nodes

\begin{tabular}{|c|c|c|c|c|c|c|c|c|c|c|}
\hline \multirow{2}{*}{ Nodes } & \multicolumn{2}{|c|}{ AODV(mS) } & \multicolumn{2}{c|}{ DSR(mS) } & \multicolumn{2}{c|}{ LAR (mS) } & \multicolumn{2}{c|}{ OLSR(mS) } & \multicolumn{2}{|c|}{ ZRP(mS) } \\
\cline { 2 - 12 } & $\begin{array}{c}\text { Statio } \\
\text { nary } \\
\text { node }\end{array}$ & $\begin{array}{c}\text { Node with } \\
\text { mobility } \\
(\mathbf{1 0 m p s )}\end{array}$ & $\begin{array}{c}\text { Statio } \\
\text { nary } \\
\text { node }\end{array}$ & $\begin{array}{c}\text { Node with } \\
\text { mobility } \\
(\mathbf{1 0 m p s})\end{array}$ & $\begin{array}{c}\text { Statio } \\
\text { nary } \\
\text { node }\end{array}$ & $\begin{array}{c}\text { Node with } \\
\text { mobility } \\
(\mathbf{1 0 m p s})\end{array}$ & $\begin{array}{c}\text { Statio } \\
\text { nary } \\
\text { node }\end{array}$ & $\begin{array}{c}\text { Node with } \\
\text { mobility } \\
(\mathbf{1 0 m p s )}\end{array}$ & $\begin{array}{c}\text { Statio } \\
\text { nary } \\
\text { node }\end{array}$ & $\begin{array}{c}\text { Node with } \\
\text { mobility } \\
(\mathbf{1 0 m p s})\end{array}$ \\
\hline 25 & 2.45 & 4.62 & 2.45 & 4.62 & 42.13 & 51.28 & 4.58 & 0.24 & 0.56 & 1.59 \\
\hline 50 & 3.76 & 2.47 & 0.67 & 6.03 & 21.1 & 5.51 & 2.34 & 0.46 & 22.15 & 3.61 \\
\hline 75 & 3.94 & 3.29 & 7.72 & 3.41 & 44.81 & 0.81 & 5.21 & 0.76 & 12.45 & 3.22 \\
\hline 100 & 1.91 & 2.52 & 5.97 & 0.15 & 23.77 & 1.02 & 0.44 & 4.84 & 22.39 & 19.27 \\
\hline 150 & 15.08 & 7.182 & 7.068 & 4.074 & 1.462 & 75.8489 & 26.854 & 38.837 & 13.575 & 41.6 \\
\hline 200 & 2.537 & 3.492 & 3.502 & 14.983 & 43.414 & 12.8908 & 48.929 & 87.295 & 18.284 & 71.017 \\
\hline 250 & 5.99 & 12.634 & 6.07 & 27.264 & 11.753 & 8.30973 & 59.161 & 145.013 & 1212.9 & 53.663 \\
\hline
\end{tabular}

\subsection{End to End Delay}

Figure7 shows the variation in end-to-end delay for mobile and stationary nodes with respect to node densities $25,50,75$ and 100 nodes and for node densities 150, 200 and 250 nodes is given in Figure8. The values of end-to-end delay for various node densities of both stationary and mobile nodes of all the protocols considered for simulation are given in table4. From Figures7 it is clear that OLSR and ZRP protocols show small variation of end-to-end delay in 25,50 and 75 nodes with mobility as compared to LAR protocol; this is due to their proactive nature. The proactive routing protocols regularly updated routing table which minimises the time taken to maintain the route [7]. However as the node density increases end-to-end delay varies in all the protocols considered for both stationary and mobile nodes.

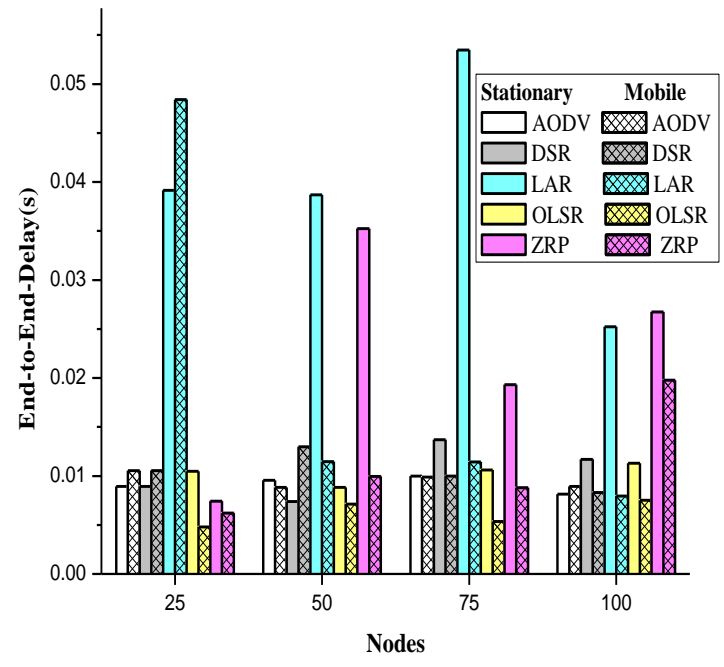

Fig 7: End-to-End Delay for25, 50, 75 and 100 stationary and mobile nodes

Table 4. End-to-End Delay of AODV, DSR, LAR, OLSR \& ZRP protocols for stationary and mobile nodes

\begin{tabular}{|c|c|c|c|c|c|c|c|c|c|c|}
\hline \multirow{2}{*}{ Nodes } & \multicolumn{2}{|c|}{ AODV(mS) } & \multicolumn{2}{c|}{ DSR(mS) } & \multicolumn{2}{c|}{ LAR(mS) } & \multicolumn{2}{c|}{ OLSR(mS) } & \multicolumn{2}{c|}{ ZRP(mS) } \\
\cline { 2 - 12 } & $\begin{array}{c}\text { Statio } \\
\text { nary } \\
\text { node }\end{array}$ & $\begin{array}{c}\text { Node with } \\
\text { mobility } \\
(\mathbf{1 0 m p s})\end{array}$ & $\begin{array}{c}\text { Statio } \\
\text { nary } \\
\text { node }\end{array}$ & $\begin{array}{c}\text { Node with } \\
\text { mobility } \\
(\mathbf{1 0 m p s})\end{array}$ & $\begin{array}{c}\text { Statio } \\
\text { nary } \\
\text { node }\end{array}$ & $\begin{array}{c}\text { Node with } \\
\text { mobility } \\
(\mathbf{1 0 m p s})\end{array}$ & $\begin{array}{c}\text { Statio } \\
\text { nary } \\
\text { node }\end{array}$ & $\begin{array}{c}\text { Node with } \\
\text { mobility } \\
(\mathbf{1 0 m p s})\end{array}$ & $\begin{array}{c}\text { Statio } \\
\text { nary } \\
\text { node }\end{array}$ & $\begin{array}{c}\text { Node with } \\
\text { mobility } \\
(\mathbf{1 0 m p s})\end{array}$ \\
\hline 25 & 8.94 & 10.536 & 8.94 & 10.536 & 39.146 & 48.403 & 10.486 & 4.805 & 7.41 & 6.208 \\
\hline 50 & 9.569 & 8.843 & 7.4 & 12.974 & 38.699 & 11.454 & 8.825 & 7.117 & 35.246 & 9.945 \\
\hline 75 & 9.998 & 9.875 & 13.7 & 9.996 & 53.465 & 11.417 & 10.605 & 5.361 & 19.315 & 8.805 \\
\hline 100 & 8.132 & 8.924 & 11.689 & 8.319 & 25.237 & 7.963 & 11.312 & 7.531 & 26.751 & 19.765 \\
\hline 150 & 23.004 & 15.524 & 17.144 & 14.71 & 19.679 & 94.361 & 37.111 & 37.005 & 51.036 & 40.62 \\
\hline 200 & 12.514 & 13.236 & 13.735 & 21.101 & 65.319 & 25.853 & 46.849 & 63.161 & 181.24 & 49.454 \\
\hline 250 & 19.415 & 24.425 & 19.965 & 30.131 & 30.81 & 16.033 & 65.159 & 109.803 & 7394.8 & 57.722 \\
\hline
\end{tabular}




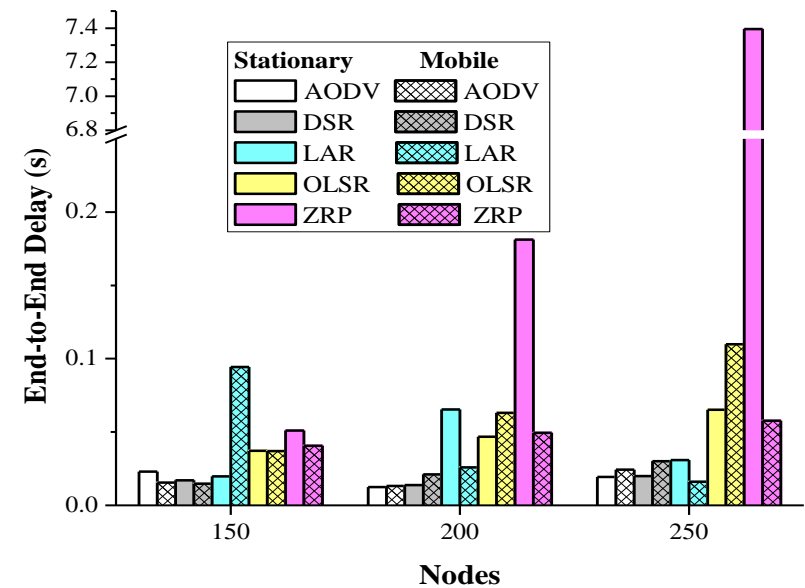

Fig 8: End-to-End Delay for 150, 200 and 250 stationary and mobile nodes

\subsection{Throughput}

Figures 9 and 10 shows the variation in throughput of various routing protocols considered for mobile and stationary nodes with respect to node densities $25,50,75 \& 100$ nodes and for node densities $150,200 \& 250$ nodes respectively. Table 5 show values of throughput for different node densities for both stationary and mobile nodes. Throughput for AODV, DSR, LAR and OLSR protocols is almost same (around 4000bps) for 25, 50, 75 and 100 stationary node scenarios (Figure9) and throughput decreases when nodes are given mobility. From the Figures9 and 10, it can easily observe that throughput in ZRP increases when nodes are given mobility. This is because, as the nodes are mobile the zone range increases and search for the active routes is managed by using inter-zone and intra-zone relay points [12] which increases the throughput.

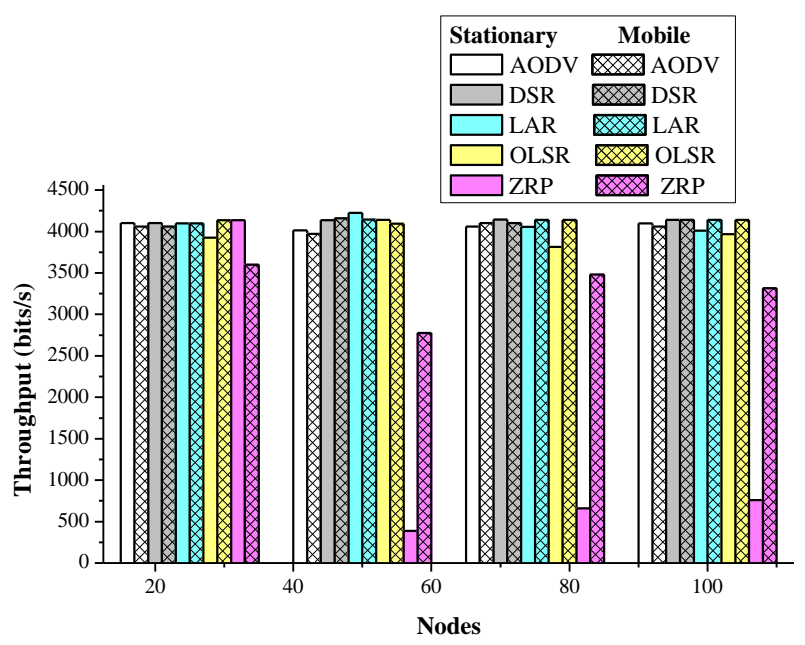

Fig 9: Throughput for 25, 50, 75 and 100 stationary and mobile nodes

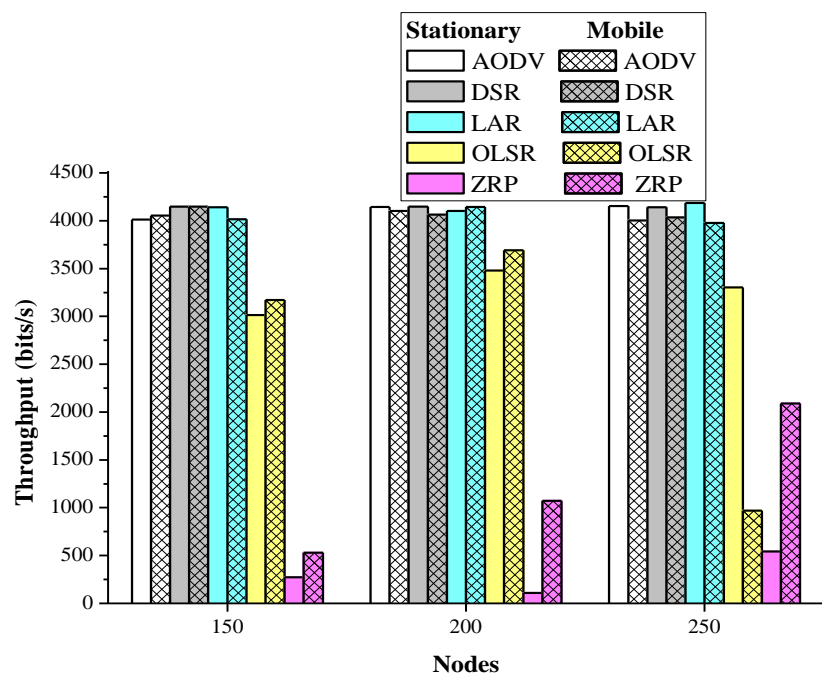

Fig 10: Throughput for 150, 200 and 250 stationary and mobile nodes

Table 5. Throughput of AODV, DSR, LAR, OLSR \& ZRP protocols for stationary and mobile nodes

\begin{tabular}{|c|c|c|c|c|c|c|c|c|c|c|}
\hline \multirow{2}{*}{ Nodes } & \multicolumn{2}{|c|}{ AODV(bits/s) } & \multicolumn{2}{c|}{ DSR(bits/s) } & \multicolumn{2}{c|}{ LAR(bits/s) } & \multicolumn{2}{c|}{ OLSR(bits/s) } & \multicolumn{2}{c|}{ ZRP(bits/s) } \\
\cline { 2 - 12 } & $\begin{array}{c}\text { Statio } \\
\text { nary } \\
\text { node }\end{array}$ & $\begin{array}{c}\text { Node with } \\
\text { mobility } \\
(\mathbf{1 0 m p s})\end{array}$ & $\begin{array}{c}\text { Statio } \\
\text { nary } \\
\text { node }\end{array}$ & $\begin{array}{c}\text { Node with } \\
\text { mobility } \\
(\mathbf{1 0 m p s})\end{array}$ & $\begin{array}{c}\text { Statio } \\
\text { nary } \\
\text { node }\end{array}$ & $\begin{array}{c}\text { Node with } \\
\text { mobility } \\
(\mathbf{1 0 m p s})\end{array}$ & $\begin{array}{c}\text { Statio } \\
\text { nary } \\
\text { node }\end{array}$ & $\begin{array}{c}\text { Node with } \\
\text { mobility } \\
(\mathbf{1 0 m p s})\end{array}$ & $\begin{array}{c}\text { Statio } \\
\text { nary } \\
\text { node }\end{array}$ & $\begin{array}{c}\text { Node with } \\
\text { mobility } \\
(\mathbf{1 0 m p s )}\end{array}$ \\
\hline 25 & 4101 & 4059 & 4101 & 4059 & 4097 & 4098 & 3926 & 4138 & 4137 & 3600 \\
\hline 50 & 4014 & 3970 & 4137 & 4161 & 4224 & 4145 & 4139 & 4096 & 386 & 2775 \\
\hline 75 & 4060 & 4101 & 4143 & 4102 & 4056 & 4139 & 3813 & 4139 & 659 & 3480 \\
\hline 100 & 4097 & 4060 & 4142 & 4142 & 4008 & 4140 & 3966 & 4139 & 758 & 3317 \\
\hline 150 & 4012 & 4055 & 4147 & 4146 & 4140 & 4016 & 3015 & 3171 & 274 & 531 \\
\hline 200 & 4143 & 4102 & 4146 & 4063 & 4101 & 4143 & 3479 & 3691 & 110 & 1072 \\
\hline 250 & 4154 & 4004 & 4140 & 4035 & 4185 & 3976 & 3304 & 970 & 542 & 2091 \\
\hline
\end{tabular}




\section{CONCLUSION}

The performance evaluation of proactive (OLSR), reactive (AODV, DSR, LAR) and hybrid (ZRP) routing protocols for stationary and mobile nodes are studied by varying the node density $(25,50,75,100,150,200$ and 250) using Qualnet 5.0.2 network simulator. From the results it can be observed that reactive routing protocols AODV and DSR are suited for applications where average jitter and throughput are very critical. ZRP, LAR and OLSR being the location based protocols need sufficient time to establish route discovery and route maintenance; hence for large range mobile applications they are best suited. OLSR is suited for large and dense mobile networks, where traffic is random and sporadic between several nodes rather than being almost exclusively between a small specified set of nodes.

\section{ACKNOWLEDGMENTS}

The authors would like to thank UGC for sanctioning the funds under major research project.

One of the authors thank the management of BHS higher Education Society, Bangalore and UGC for the author to avail FIP.

Authors would also thank Nihon communication, Bangalore for simulation tool.

\section{REFERENCES}

[1] LOCCATEC: Low Catastrophic Event -2000-29401, www.loccatec.org

[2] N.Vetrivelan and A.V.Reddy, 2008. "Performance Analysis of Three routing Protocols for Varying MANET Size", Proceedings of the International Multi-Conference of Engineers and Computer Scientists.

[3] M.Uma and G.Padmavathi, 2009. "A Comparative Study and Performance Evaluation of Reactive Quality of Service Routing Protocols in MANETs", Journal of Theoretical and Applied Information Technology, pp. 223229

[4] Wireless routing protocols, http://www.wikipedia.com

[5] QualNet Network Simulator; Available: http://www. scalable-networks.com.

[6] E.M.Royer and C.K.Toh, 1999. "A Review of Current Routing Protocols for Ad-Hoc Mobile Wireless Networks", IEEE Personal Communications Magazine, 46-55.

[7] Philippe Jaquet, Paul Muhlethaler and Amir Qayyum, 2001. "Optimized Link State Routing Protocol", IETF Draft, http://www.ietf.org/internet-drafts/draft-ietf-manetolsr-06.txt

[8] Syed Basha Shaik, S. P. Setty, 2010. "Performance Comparison of AODV, DSR and ANODR for Grid Placement Model" International Journal of Computer Applications (0975 8887), Volume 11, No.12, 6-9.

[9] C. E. Perkins and E. M. Royer, 1999. "Ad Hoc On-demand Distance Vector Routing," In Proceedings of the 2nd IEEE Workshop on Mobile Computing Systems and Applications, New Orleans, LA, 90-100.
[10] Young-Bae Ko and Nitin H. Vaidya, 1998. "Location-aided routing (lar) in mobile ad hoc networks". Technical report, Department of Computer Science Texas A\&M University, College Station, TX 77843-3112.

[11] D.Johnson, D.Maltz and Yih, 2003. "Dynamic Source Routing Protocol for Mobile AdHoc", http://www.ietf.org/internet-drafts/ draft ietf manet-DSR09.txt, IETF Internet draft,

[12] SreeRangaRaju and Jitendranath Mungara. 2010. "Performance Evaluation of ZRP over AODV and DSR in Mobile Adhoc Networks Using Qualnet" European Journal of Scientific Research, Vol. 45, No.4. 658-674.

[13] A.Boukerche, 2004. "Performance Evaluation of Routing Protocols for Ad Hoc Wireless Networks," Mobile Networks and Applications, Vol. 9, Kluwer Academic Publishers, 333-342.

[14] D.A.Broch, D.B.Maltz,. Johnson, Y-C Hu and J. Jetcheva, 1998. "A Performance Comparison of Multihop Wireless Ad Hoc Network Routing Protocols," In Proceedings of MOBICOMM.

[15] S. R. Das, R. Castaneda and J. Yan, 1998. "Simulation Based Performance Evaluation of Mobile Ad Hoc Network Routing Protocols", In Proceedings of Seventh International Conference on Computer Communications and Networks.

[16] S.R.Das, C.E.Perkins and E. M. Royer, 2000. "Performance Comparison of Two On-Demand Routing Protocols for AdHoc Networks," In Proceedings of INFOCOM 2000

[17] Hong Jiang, 1994. "Performance Comparison of Three Routing Protocols for Ad Hoc Networks", Communications of the ACM, Vol. 37.

[18] J.Broch, D.A.Maltz, David B.Johnson, Y. Hu and J. Jetcheva, 1998. "A Performance Comparison of Multi-Hop Wireless Ad-hoc Network Routing Protocols", Proceedings of the Fourth Annual ACM/IEEE International Conference on Mobile Computing and Networking, MobiCom'98, 2530.

[19] Boukerche, 2001. "Performance Comparison and Analysis of Ad Hoc Routing Algorithms," In Proceedings of IPCCC 2001, USA, 171-178.

[20] S.Azad, A.Rahman and F.Anwar, 2007. "A Performance Comparison of Proactive and Reactive Routing Protocols of Mobile Ad-hoc NETwork (MANET)", Journal of Engineering and Applied Sciences 2(5), 891-896.

[21] QualNet documentation, "QualNet 5.0 Model Library: Advanced Wireless"; http://www.scalablenetworks.com /products/Qualnet/download.php\#docs 